\title{
Discrete and time-integrated sampling for chromium load calculations in a watershed with an impoundment reservoir at an exceptionally low water level
}

\author{
Ewa Szalinska • Agnieszka Smolicka • Janusz Dominik
}

Received: 31 July 2012 /Accepted: 12 November 2012 / Published online: 8 December 2012

(C) The Author(s) 2012. This article is published with open access at Springerlink.com

\begin{abstract}
Instantaneous (discrete) and time-integrated (composed) samples were collected during a 19-week period in a watershed impacted by discontinuous discharges from local tanneries (Carpathians Mountains, Poland). Existence of the impoundment reservoir in this watershed allowed investigation of its role in chromium transport. In collected samples, dissolved and particulate chromium concentrations were measured to apportion both loads. This study has demonstrated that the impoundment reservoir retains not only particulate but also a dissolved form of chromium and its efficiency reaches 74-94\%. Sampling results proved that chromium contamination in the investigated river is variable and discontinuous. Discrete sampling can lead to an underestimation of chromium contamination level (up to $78 \%$ ), especially when illegal/unexpected discharges occur in the watershed. A discrete sampling regime also produces less reliable data for contaminant budget calculations, especially in sites where strong variability of contamination is anticipated, while at the output from
\end{abstract}

Responsible editor: Philippe Garrigues

E. Szalinska $(\triangle) \cdot$ A. Smolicka

Institute of Water Supply and Environmental Protection, Cracow

University of Technology, 31-155 Cracow, ul.,

Warszawska 24, Poland

e-mail: eszalin@pk.edu.pl

J. Dominik

Institute F.-A. Forel, University of Geneva, 10, route de Suisse, 1290 Versoix, Switzerland

\section{Present Address:}

J. Dominik

Istituto di Scienze Marine-Consiglio Nazionale delle Ricerche,

Arsenale-Tesa 104, Castello 2737/F,

30122 Venice, Italy reservoirs, the load can be reasonably estimated using this mode of sampling.

Keywords Sampling strategy $\cdot$ Chromium $\cdot$ Load estimation · Fluctuating sources $\cdot$ Impoundment reservoir

\section{Introduction}

Application of monitoring data instead of estimated or predicted values for contaminant concentrations is crucial for accurate flux estimation. Therefore, representativeness and reliability of these data, reflecting the contaminant source characteristic, should be assured. Enhanced knowledge of the temporal and spatial patterns of contaminant distribution improves effectiveness of collection of monitoring data. Since these patterns are not uniform in aquatic environments, a carefully designed sampling regime should be considered for each system.

Routine monitoring of contaminants in fluvial systems is generally performed by discrete sampling at various spatiotemporal scales. Fluvial systems receiving pollutant from discontinuous or fluctuating point sources may not be adequately monitored with discrete sampling, and for chemical monitoring various, cost-effective methods can be developed, tested, and applied (for review see Allan et al. 2006). Nevertheless, given that a majority of European rivers are fragmented, the portions of rivers downstream larger impoundments can possibly be monitored using discrete sampling provided an adequate sampling frequency is determined.

In a watershed with an impoundment reservoir entrapment of the contaminant particulate load can be expected. Globally, the reservoir trap efficiency is estimated at more than $50 \%$ (Vörösmarty et al. 2003) and for larger 
reservoirs, frequently reported as $80-90 \%$ of the sediment volume delivered from the watershed (Sundborg 1992). As sediments provide means of transport and removal of particle-reactive compounds, the rough estimation of their loads introduced into the reservoir may be based on the sediment computation, and estimating the fraction of the contaminant present in the total load of sediment. However, more frequently, contaminant loads are estimated as the product of concurrent flow and contaminant concentration measurements. Due to high variability of particulate species concentrations, load estimation is sensitive to sampling timing and frequency (e.g., Salles et al. 2008). Since, frequency is strongly limited by costs of sample collection, transport, and analyses, studies relying on continuous and automatic sampling are highly desirable. Continuous modes of sampling not only account better for temporal variability of load than discrete sampling, but also better integrates the partitioning between dissolved and particulate factions (Priadi et al. 2011).

The upper Dunajec River watershed (Carpathians Mountains, Poland) with the Czorsztyn Reservoir (231.9 million cubic meter, 70 days of mean retention) creates a useful setup for monitoring investigation. Chromium originating from local tanneries is the only metal contamination in this watershed. Effluents contaminated with chromium, used as a tanning agent, are discharged into the Dunajec River and then transported to the reservoir (Szalinska 2002; Szalinska et al. 2010). Although the tannery waste waters are partly treated in a sewage treatment plant, numerous small tanneries (about 300) discharge effluents directly into the river, resulting in a highly variable load. Water quality monitoring is carried out in this watershed by statutory authorities, however, the frequency of chromium measurements and localization of sampling sites is strongly limited (discrete sampling four times per year, only riverine samples). The Czorsztyn Reservoir has been constructed mainly to protect the area against floods but also to produce green energy. Operation of the hydroelectric power plant (Niedzica) located in the main dam required the construction of the compensatory reservoir (Sromowce; 7.5 million cubic meter, 5 days of retention).

An exceptionally low water level in the impoundment reservoir (Czorsztyn) during the sampling time, due to decadal maintenance operations, allowed us to study chromium retention and release. At such conditions, retention is being modified by shorter water residence time and release by erosion of exposed (emerged) sediments. However, the primary goal of this study was to compare results of two sampling strategies (discrete and continuous) to estimate fluxes in a situation of discontinuous character of contaminant inputs, and to suggest a sampling pattern which would produce reasonably accurate load estimates. We focused our investigation on both forms of chromium (particulate and dissolved) in attempt to establish their fate and share in total loads.

\section{Materials and methods}

Sampling area and sample collection

Water samples from the river and outlets of both reservoirs were collected at three sampling sites (Fig. 1). Site 1 was localized on the Dunajec River (inside a small hydroelectric power plant facility). Samples from the reservoirs were collected at the outlets from the Czorsztyn (site 2, at the Niedzica hydroelectric power plant) and Sromowce Reservoirs (site 3, at the Sromowce hydroelectric power plant). Sampling had been carried out for 19 weeks (19 sampling series), between November 29, 2007 and April 9, 2008. During this period, instantaneous (discrete) and integrated (composed) samples were collected. Winter was chosen to cover the period of increased tanning activity, occurring from November to March (Szalinska 2002; Szalinska et al. 2010). The exceptionally low water level in the Czorsztyn Reservoir was observed at the end of 2007 and the beginning of 2008, due to decadal hydroelectric power plant maintaining procedures.

Discrete samples were collected weekly at all three sites using $\mathrm{HNO}_{3}$-washed, polyethylene bottles. Water was filtered through pre-weighed $0.45-\mu \mathrm{m}$ filters (cellulose acetate) directly after sampling and filters were preserved to assess particulate matter and particulate $\mathrm{Cr}$ concentrations. Filtrates for total dissolved $\mathrm{Cr}$ were acidified with $\mathrm{HNO}_{3}$ (ACS grade) to a pH below 2 .

Integrated samples were collected at all three sites using automatic water samplers (ISCO) in the time-integrated mode. This mode rather than the discharge proportional mode was chosen for a better comparison with the discrete sampling. Samples at site 1 were composed at regular 2$\mathrm{h}$ intervals to obtain daily average samples. At sites 2 and 3, weekly average samples were obtained by mixing equal volumes of the daily averages. Such a strategy was adopted due to the high variability of flows and $\mathrm{Cr}$ concentrations at site 1 (Dunajec River) and low variability at sites 2 and 3, due to the buffering capacity of the reservoirs. To prevent $\mathrm{Cr}$ loss from the solution during storage, $2 \mathrm{ml} 16 \mathrm{M} \mathrm{HNO}_{3}$ (ACS grade) was added to the containers to assure a final $\mathrm{pH}$ below 2. After termination, each of the week-series samples were filtered $(0.45 \mu \mathrm{m})$ and containers were $\mathrm{HNO}_{3}$ and deionised water washed. Concentrations measured in the water were considered as "labile" $\mathrm{Cr}$ concentrations, as a part of $\mathrm{Cr}$ weakly bound to particles was released at $\mathrm{pH}<2$.

Laboratory and statistical analyses

Particulate matter $\mathrm{Cr}$ extraction was performed according to the Osol protocol (Osol 1986) in an ultrasonic mineralizator (ULTRAsonic $104 \times$ ) with $2 \mathrm{~N}^{-1 N O}$. Samples were then heated at $100{ }^{\circ} \mathrm{C}$ for $12 \mathrm{~h}$ and allowed to cool. After 
Fig. 1 Overview of the sampling area and localization of sampling sites

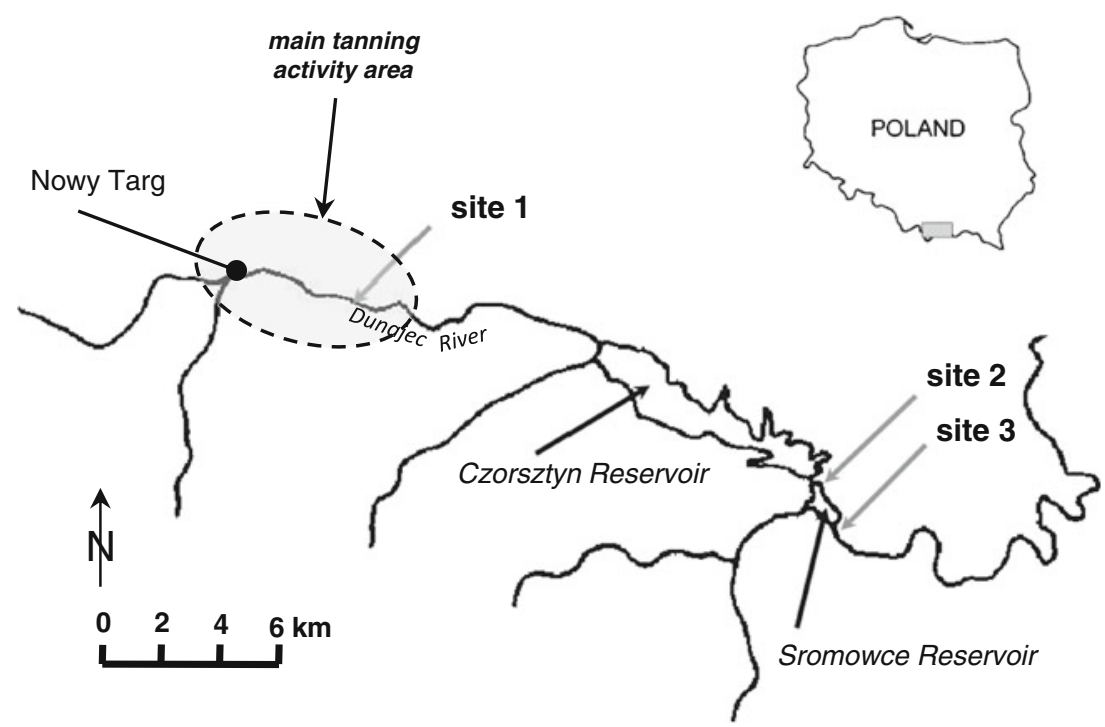

centrifugation $(4,000 \mathrm{rpm}$ for $20 \mathrm{~min})$, supernatants were diluted with $1 \% \mathrm{HNO}_{3}$ before measurement. Due to a small amount of particulate matter retained on the filters, not all were subjected to extraction.

$\mathrm{Cr}$ concentrations were measured in filter extracts and water samples by ICP-OES (OPTIMA 2000, Perkin Elmer) at the Inspectorate for Environmental Protection Laboratory. During $\mathrm{Cr}$ analyses, calibration solutions, blanks, and standards were run every 10 samples with a detection limit of $0.01 \mu \mathrm{gl}^{-1}$. Precision was monitored by running duplicates of any two real samples placed in random order within every 10 samples. Replicate measurements agreed within less than $5 \%$. To assess contamination, method blanks and filtration blanks were randomly processed through the procedure. Filtration blanks were below reported detection limits. Accuracy was assured through the use of an in-house reference material according to the PNEN ISO 11885:2009 norm. Percentage recovery of $\mathrm{Cr}$ with respect to referred values was in the $90-110 \%$ range.

General statistical analyses were produced using Excel v. 2007. To assess relationship and significant differences among the individual series, Spearman's rank correlation and Mann-Whitney $U$ tests were performed using Stagraphics Centurion XV. Regression analysis between discharge, suspension concentrations, and partition coefficients were carried out using Sigmaplot 11 software.

\section{Results}

Chromium concentrations

Dissolved $\mathrm{Cr}$ concentrations $\left(\mathrm{Cr}_{\text {diss }}\right.$, filterable fraction) in instantaneous samples at site 1 were higher than at sites 2 and 3 during all 19 sampling series. They were in the range of $1.7-13.7 \mu \mathrm{gl}^{-1}$, while the highest value observed at the other sites was $2.1 \mu \mathrm{gl}^{-1}$ (Table 1). This form of chromium displayed no specific temporal pattern and no correlations with river flow or reservoir discharge have been observed.

The highest particulate matter concentration $\left(29 \mathrm{mgl}^{-1}\right)$ was observed in a sample from site 1 collected on March 19, 2008. Generally, in all the remaining samples this parameter was higher in samples from site 2 than in sites 2 and 3 , and remained below $10 \mathrm{mgl}^{-1}$. Particulate matter concentrations were related to the flow only at site 1 , and this relationship was significant at the $p=0.05$ level. The highest $\mathrm{Cr}$ particulate concentration $\left(\mathrm{Cr}_{\text {part }}\right.$ in $\left.\mu \mathrm{gl}^{-1}\right)$ was observed in a sample collected on March 19, 2008 at site 1 (Fig. 2). Also at this site, the mean value, for this portion of $\mathrm{Cr}$ in the whole investigated period $\left(99.9 \pm 79.3 \mu \mathrm{gl}^{-1}\right)$ was the highest (Table 1). For the remaining sites, $\mathrm{Cr}$ particulate concentrations were below $56 \mu \mathrm{gl}^{-1}$.

Partition coefficients $K_{\mathrm{d}}$ (ratio between $\mathrm{Cr}$ in suspension microgram per kilogram and $\mathrm{Cr}_{\text {diss }}$ microgram per liter) were in the range of $5.0 \cdot 10^{5}-1.2 \cdot 10^{7} 1 \mathrm{~kg}^{-1}\left(\log K_{\mathrm{d}} 5.7-7.1\right)$ and were higher than the range presented in a previous study from the Dunajec River (Szalinska 2002). This difference was caused both by lower $\mathrm{Cr}$ concentrations in the dissolved fraction combined with higher $\mathrm{Cr}$ concentrations in particulate matter in the present study. The reason for higher $K_{\mathrm{d}}$ values is unknown, but it should be noted that the present study covers only the winter period and might not necessarily be representative of the whole year.

Despite the fact that labile $\mathrm{Cr}$ concentrations $\left(\mathrm{Cr}_{\mathrm{lab}}\right)$ in the integrated samples did not display a normal distribution, the subsequent descriptive statistic is presented as a mean value, instead of median and first and third quartile to facilitate the comparison between different types of sampling. $\mathrm{Cr}_{\text {lab }}$ showed the highest variability at site 1 . Measured values at this site were in the range of $0.6-895.9 \mu \mathrm{gl}^{-1}$ with a mean value of $24.3 \pm 84.4 \mu \mathrm{gl}^{-1}$ (Table 1). Integrated samples 
Table 1 Dissolved and particulate $\mathrm{Cr}$ concentrations in instantaneous and integrated samples at sampling sites (all concentrations in microgram per liter)

\begin{tabular}{|c|c|c|c|c|c|c|c|c|c|c|c|c|}
\hline \multirow{2}{*}{$\begin{array}{l}\text { Site } \\
\text { Cr form }\end{array}$} & \multicolumn{4}{|l|}{1} & \multicolumn{4}{|l|}{2} & \multicolumn{4}{|l|}{3} \\
\hline & Min & Max & Mean & RSD (\%) & Min & Max & Mean & RSD (\%) & Min & $\operatorname{Max}$ & Mean & RSD (\%) \\
\hline \multicolumn{13}{|c|}{ Instantaneous samples } \\
\hline $\mathrm{Cr}_{\text {diss }}$ & 1.7 & 13.7 & 6.0 & 66 & 0.2 & 2.1 & 1.1 & 43 & 0.4 & 1.5 & 0.9 & 34 \\
\hline $\mathrm{Cr}_{\text {part }}$ & 15.1 & 241 & 99.9 & 79 & 20.6 & 55.6 & 41.9 & 38 & 51.9 & - & & \\
\hline \multicolumn{13}{|c|}{ Integrated samples } \\
\hline $\mathrm{Cr}_{\text {diss }}$ & 0.6 & 876 & 23.7 & 348 & 1.0 & 3.1 & 1.9 & 28 & 0.4 & 2.1 & 1.7 & 68 \\
\hline $\mathrm{Cr}_{\text {lab }}$ & 0.6 & 896 & 24.3 & 348 & 1.0 & 3.2 & 2.0 & 28 & 0.4 & 2.2 & 1.8 & 68 \\
\hline
\end{tabular}

$C r_{\text {diss }}$ Total $\mathrm{Cr}$ concentrations in dissolved phase, $C r_{\text {part }} \mathrm{Cr}$ concentration associated with particles, $C r_{\text {lab }} \mathrm{Cr}$ concentration in dissolved and partially desorbed from the particulate fraction, $R S D$ relative standard deviation

collected at sites 2 and 3 had $\mathrm{Cr}$ concentrations within the range of $0.4-3.2 \mu \mathrm{gl}^{-1}$.

Chromium loads computation

The most common approaches to compute river fluxes from concentration and flow data are presented by Webb et al. (1997, 2000) and Johnes (2007). These mainly include interpolation methods, assuming that the measured concentrations are representative for a fixed period between sampling, and also extrapolation procedures, developing a rating relationship between concentration and flow at the time of sampling that is applied subsequently to estimate load in the period of interest. These methods are commonly used to produce solute, and particle-associated riverine fluxes. In the case of our study, where different time-integrated averaging methods were used to collect samples, and also dissolved and particulate $\mathrm{Cr}$ concentrations were used to calculate loads, a flexible adaptive strategy has been applied to obtain the most reliable load values.
Generally, dissolved and particulate $\mathrm{Cr}$ loads were computed as the product of flow volume $\mathrm{Cr}$ and concentration measured during the corresponding time interval using Eq. 1:

Load $=\sum_{i=1}^{n} q_{i} \times c_{i} \times t$

where: $n$-number of samples, $q_{l}$ - the $i$ th water discharge, $c_{i}$ - the $\mathrm{Cr}$ concentration in the $i$ th sample, and $t$ - the time interval. Mean daily Dunajec River flows from the investigated cross-section (site 1, average value for the entire sampling period $-12.8 \mathrm{~m}^{3} \mathrm{~s}^{-1}$ ) and mean daily reservoirs discharges (sites 2 and 3, average value for the entire sampling period $-18.8 \mathrm{~m}^{3} \mathrm{~s}^{-1}$ and $15.9 \mathrm{~m}^{3} \mathrm{~s}^{-1}$, respectively). Flow data were kindly provided by the Niedzica Power Plant.

To calculate the dissolved load at site 1 from discrete samples, the measured concentrations $\left(\mathrm{Cr}_{\text {diss }}\right)$ were multiplied by mean water discharge during the week preceding the sampling date. This was preferred than the discharge
Fig. 2 Distribution of dissolved and particulate $\mathrm{Cr}$ concentrations in instantaneous and integrated samples at site 1 (Dunajec River)

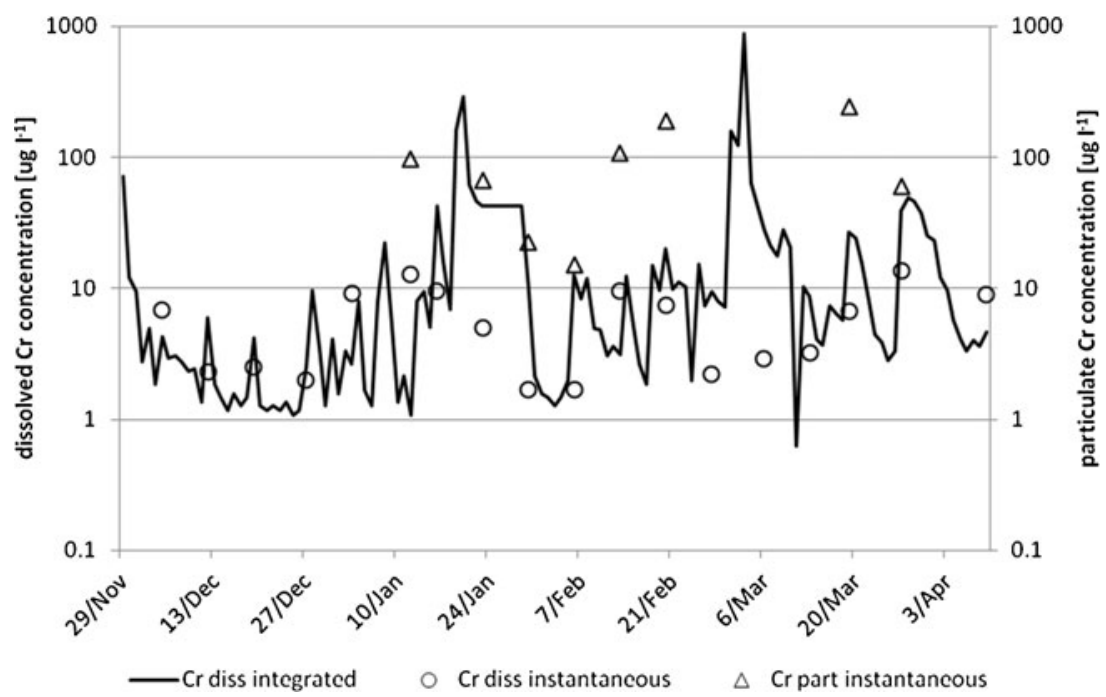


measured on the sampling date as there was no correlation between discharge and dissolved concentration and the water discharge varied markedly during some weeks. The errors attributed to the discharges corresponded to $1 \mathrm{SD}$ of weekly means and the errors of dissolved concentrations were taken as $1 \mathrm{SD}$ of the mean concentration from the whole period of measurements. These errors were then propagated to the weekly and total loads for the period of observation. The load at sites 2 and 3 were calculated from mean weekly discharges and concentrations for the corresponding periods.

Particulate load at site 1 in discrete samples was calculated as the particulate $\mathrm{Cr}$ concentration $\left(\mathrm{Cr}_{\text {part }}\right.$, milligram per liter) multiplied with the mean discharge on the sampling days and assumed to be constant during the week between the sampling dates. $\mathrm{Cr}_{\text {part }}$ was calculated from concentration of chromium in suspended particles $\left(\mathrm{Cr}_{\text {sus }}\right.$, microgram per gram) by the suspended particle concentration ( $z$, milligram per liter). Analytical error of $\mathrm{Cr}_{\text {sus }}$ and the estimated error of suspended particle measurement $(0.05 \mathrm{mg}$ $1^{-1}$ ) were propagated. For three samples with missing particle concentration data, the estimated values were calculated from water discharge using a second degree polynomial regression: $z=9.012-1.609 q+0.082 \mathrm{q}^{2}\left(r^{2}=0.59, p=\right.$ 0.005). Standard error of estimation (5.0) was attributed to obtained concentrations. Missing values of $\mathrm{Cr}_{\text {part }}$ were estimated from a log-log regression between suspended particle concentrations and a partitioning coefficient $\left(K_{\mathrm{d}}\right.$;). Such dependence is often observed and can be explained by the "particle concentration effect" (Honeyman and Santschi 1992). This relation $\left(\log K_{\mathrm{d}}=6.907-0.713 \log \mathrm{z} ; r^{2}=0.57\right.$, $p=0.029)$ and the measured $\mathrm{Cr}_{\text {sus }}$ allowed the estimation of $\mathrm{Cr}_{\text {part }}$. The attributed errors corresponded to the $95 \%$ confidence interval of the regression. After conversions from logarithms the errors were asymmetric, and thus the lower and upper error range was given in the estimation of uncertainty of the budget. Chromium particulate load for the whole period was then calculated as for the dissolved load. It should be noted that about $25 \%$ of the total $\mathrm{Cr}$ particulate load is due to one event on March 19th when high concentrations of suspension $\left(28.7 \mathrm{mgl}^{-1}\right)$ and $\mathrm{Cr}_{\text {part }}\left(241 \mu \mathrm{gl}^{-1}\right)$ were measured.

Particulate $\mathrm{Cr}$ load for sites 2 and 3 in discrete samples were estimated in a similar manner. A few missing values of $\mathrm{Cr}_{\text {sus }}$ were estimated by interpolation and the errors of estimation from relative standard deviations of the mean from the whole period of observation. Similarly, at site 1, the missing $\mathrm{Cr}_{\text {part }}$ values were obtained from $\log \mathrm{Cr}_{\text {sus }}$ vs. $\log K_{\mathrm{d}}$ relation from these sites $\left(\log K_{\mathrm{d}}=7.73-1.41 \log z\right.$; $r^{2}=0.83, p=0.031$ ).

Given that integrated samples were collected in bottles containing $\mathrm{HNO}_{3}$ assuring a final $\mathrm{pH}$ below 2, measured concentration in filtered samples can be considered as a labile fraction $\left(\mathrm{Cr}_{\text {lab }}\right)$ of total chromium. Daily loads for site 1 and weekly for sites 2 and 3 were calculated by multiplying these concentrations with the respective water discharges. Errors attributed to the loads were obtained by propagation of analytical errors and water discharge error, the latter arbitrary assumed to be $5 \%$. Dissolved concentrations $\left(\mathrm{Cr}_{\text {diss }}\right)$ were estimated as the measured concentration $\left(\mathrm{Cr}_{\text {lab }}\right)$ minus a corrective expression $\mathrm{Cr}_{\text {part }} \times 0.022 \pm$ 0.010 to account for the amount of $\mathrm{Cr}$ desorbed from suspension in receiving bottles due to the addition of acid. The fraction desorbed was estimated from a pair wise comparison between dissolved concentrations in instantaneous and weekly integrated samples at sites 2 and 3. For these sites located at the exits from the reservoirs, it can be safely assumed that the dissolved concentrations in the instantaneous and integrated samples are very similar due to the buffering capacity of the reservoirs. Due to a high variability of concentrations such an assumption may not be valid at site 1 and thus the corrective factor obtained from sites 2 and 3 was also applied to site 1 , assuming that the desorbed fraction is the same. The error of dissolved concentration $\left(\mathrm{Cr}_{\text {diss }}\right)$ was obtained by propagation of the error of $\mathrm{Cr}_{\text {part }}$ (taken as RSD of the mean from the whole period of measurements) and standard deviation of the corrective factor. To obtain a daily load at site $1, \mathrm{Cr}_{\text {diss }}$ was multiplied by the daily water discharge and the error adjusted, assuming a $5 \%$ uncertainty of daily water discharge. As for all other load estimations in this paper, the daily load was then summed for the whole period of measurements (November 29, 2007April 9, 2008). It was assumed that the errors are randomly distributed and were propagated accordingly. For sites 2 and 3 , the procedure was the same except that the mean weekly concentrations and water discharge were used.

Total dissolved and particulate $\mathrm{Cr}$ loads computed for the period of November 29, 2007-April 9, 2008 during instantaneous sampling were high at site 1 as compared to site 2 where the respective loads were lower by 74 and $42 \%$ (Table 2), emphasizing the high efficiency of the reservoir in trapping of $\mathrm{Cr}$ loads. Dissolved and particulate $\mathrm{Cr}$ loads for site 3 were only marginally smaller than for site 2 (non significant difference). The projected errors were below 25 and $75 \%$ for dissolved and particulate loads, respectively, except of the upper limit of particulate load at site 3 which is unrealistically high. This result came from an extremely high upper limit of $K_{\mathrm{d}}$ error for one sample with very low suspension concentration. If the load for this particular week is obtained from interpolation of loads from the previous and following weeks, the particulate load at site 3 would be $6.0(+2.9 ;-1.0)$ instead of the load given in Table 2. Dissolved $\mathrm{Cr}$ loads obtained for integrated samples at site 1 were 3.6-5.4 times higher than for instantaneous ones. At sites 2 and 3, the dissolved loads obtained from discrete and integrated samples were the same. 
Table 2 Estimated dissolved and particulate Cr loads (tons) with errors for instantaneous and integrated sampling during the investigated period (November 29, 2007-April 9, 2008)

\begin{tabular}{llclll}
\hline Site & \multicolumn{2}{l}{ Instantaneous samples } & & \multicolumn{2}{l}{ Integrated samples } \\
\cline { 2 - 3 } & $\mathrm{Cr}_{\text {diss }}$ & $\mathrm{Cr}_{\text {part }}$ & & $\mathrm{Cr}_{\text {lab }}$ & $\mathrm{Cr}_{\text {diss }}$ \\
\hline 1 & $0.82 \pm 0.18$ & $11.2(+3.3 ;-1.3)$ & & $3.64 \pm 0.05$ & $3.42 \pm 0.05$ \\
2 & $0.21 \pm 0.03$ & $6.5(+4.2 ;-0.9)$ & & $0.33 \pm 0.01$ & $0.20 \pm 0.02$ \\
3 & $0.17 \pm 0.01$ & $6.6(+18.1 ;-1.0)$ & & $0.32 \pm 0.01$ & $0.17 \pm 0.03$ \\
\hline
\end{tabular}

$C r_{\text {diss }}$ total $\mathrm{Cr}$ concentrations in dissolved phase, $\mathrm{Cr}_{\text {part }}$ concentration of the $\mathrm{Cr}$ fraction associated with particles, $\mathrm{Cr}_{l a b}$ Labile fraction of total Cr concentration

\section{Discussion}

Applied sampling strategy, including discrete and continuous sampling, allowed precise tracking of contaminant levels in the investigated watershed prior to the load considerations. The results also quantified previously published qualitative findings (Szalinska et al. 2010) on chromium transport in dissolved and particulate phases in the upper section of the Dunajec River. $\mathrm{Cr}$ in the particulate phase constituted $93 \pm 3 \%$ of total chromium. Considering high contribution of the particulate $\mathrm{Cr}$ and association with colloids (Dominik et al. 2003, 2007), removal of chromium from the water column and its sedimentation in the reservoir can be expected.

The ranges of particulate and dissolved $\mathrm{Cr}$ concentrations observed in the discharge from the impoundment reservoir (site 2) were substantially lower than in riverine samples. This suggests that transport of water through the reservoir (Czorsztyn) contributes not only to the removal of particulate chromium, which is a well-known process in large reservoirs (e.g., Klaver et al. 2007), but also removal of $\mathrm{Cr}$ from the dissolved phase. The latter is probably related to the "colloidal pumping" process since entrapment of $\mathrm{Cr}$ colloidal forms was also observed in this reservoir (Dominik et al. 2003, 2007). Further transport through the compensatory reservoir (Sromowce), where the water retention time is short, did not produce any noteworthy changes in $\mathrm{Cr}$ levels, both in the dissolved and particulate phases. $\mathrm{Cr}$ concentrations in instantaneous samples from site 2 and 3 were comparable, and significantly correlated in time at a $p=$ 0.05 level. Despite low total chromium concentrations in samples from the reservoir outlets, $\mathrm{Cr}$ in particulate phase constituted even a higher percentage $(97 \%)$ of the total chromium than at site 1 . This was due to the higher concentrations of particulate matter in the samples from the reservoir outlet.

Particulate matter concentrations were higher in the outlet from the impoundment reservoir (site 2) than in the river (site 1) from December until mid-January and also in
February, which is quite unusual in such a system. In the comparable period of 2001 , concentrations of particulate matter measured in the river just downstream from site 3, were at a level of $1.4 \mathrm{mgl}^{-1}$, and always smaller than at site 1 (Szalinska et al. 2010). As mentioned previously, the water level in the reservoir was exceptionally low because of the decadal program of dam inspection carried out in the end of 2007 and the beginning of 2008. Lowered water level, by approximately $10 \mathrm{~m}$, exposed large areas of reservoir sediments to the atmosphere. A relatively high concentration of particles in the reservoir outlet may result from the exposure of the sediments to erosion, caused by wind, rain, and snow melt. Erosion could be attenuated during winter months (January-February), when sediments were completely covered with snow, and increased again during snow melt (March-April). Moreover, high flows of the river entering the reservoir during the snow melting period could additionally erode material from the air-exposed delta. However, because of lower concentrations of $\mathrm{Cr}$ in the reservoir sediments (Szalinska et al. 2010) than in suspended particles of the river, the net retention of particulate chromium is still close to $50 \%$. This value can be considered as a lower limit and is certainly much higher than at a normal operating level of the reservoir. This observation is rather important because it demonstrates that at a lower water level in the impoundment reservoir, contaminants stored in the sediments can be mobilized to the downstream section of the river, without a deliberate sediment purge.

Removal of dissolved and particulate chromium into the reservoir sediments is also clearly visible when comparing input-output $\mathrm{Cr}$ loads (Table 2). Generally, dissolved $\mathrm{Cr}$ loads for the entire 19 weeks of sampling decreased 3.9 and 17.1 times between sites 1 and 2, for the instantaneous and integrated samples respectively. For the particulate form of chromium, this decrease was smaller, reaching 1.7 times, due to the higher concentration of particulate matter at site 2 . As a part of these particles probably originate from sediments prone to erosion at the exceptionally low water level, the trapping of particulate $\mathrm{Cr}$ during normal conditions is probably more efficient. Retention capacity of the compensatory reservoir was low; not significant for dissolved (about 15-19\%) and undetectable for particulate forms.

Temporal evolution of chromium in instantaneous samples at site 1 did show high variability and no specific pattern in any of the sampling sites through the whole sampling period. A more detailed picture of the chromium transport was obtained from the results of continuous sampling. Dissolved $\mathrm{Cr}$ concentrations in integrated riverine samples were generally higher $(72 \%$ of the total number of samples) than in instantaneous samples collected on the same days (Fig. 2). These differences, reaching 10-78\%, resulted from the diverse time and mode of sampling. Integrated samples represent daily average $\mathrm{Cr}$ concentrations 
while instantaneous samples were collected in the morning of the sampling day. Since these concentrations were not related to the river flow, we can assume that the volume of tannery wastewater discharged into the river is highly variable. Analyzing temporal trends within integrated samples, the increase of $\mathrm{Cr}$ concentrations at the beginning and at the end of the week (Saturday through Monday) is noticeable and also causes increase of the $\mathrm{Cr}$ loads (Fig. 3). This can be related to the production cycle in the local tanneries through delivery of Cr-contaminated wastewater to the treatment plants on Mondays and its illegal discharges into the aquatic environment on weekends.

Such a temporal evolution of $\mathrm{Cr}$ concentrations raises the question of timing and frequency in water monitoring for this and similar systems. In the current study, instantaneous samples were collected usually on Wednesdays in the morning hours due to convenience reasons (schedule of the laboratory work). Since there is no significant correlation between dissolved $\mathrm{Cr}$ concentrations in samples collected in instantaneous and integrated modes $\left(r^{2}=0.05\right.$ at $\left.p=0.39\right)$, we can deduce that not only the choice of the weekday but also sampling hour is significant. Higher concentrations in integrated samples suggest that illegal chromium discharges happen most likely during evening hours as reported in a previous study (Szalinska 2002).

The issue of sampling regime also affects estimation of the chromium load introduced into the reservoir. Assuming for estimation purposes that dissolved $\mathrm{Cr}$ concentrations from integrated samples would represent instantaneous values, the difference in load calculated for sampling carried on Wednesdays or Sundays would amount to $78 \%$. Taking these differences into consideration and also the uncertainty of error values estimated for the dissolved and particulate $\mathrm{Cr}$ loads for instantaneous samples (Table 2), it becomes clear that timeintegrated sampling is the only reliable method not only to reflect spatio-temporal trends in contaminant variation trends
(Priadi et al. 2011), but also for collecting data for load estimations of contaminants from fluctuating point sources. Instantaneous sampling, even if frequent, is not suitable for contaminant budget calculations for sites were the presence of highly variable sources of contamination is expected. It should be also noted that the errors of load calculation are mainly based on propagation of measurement errors or on estimated variability of parameters for time intervals not covered by measurements. If the variability of parameters is higher than the estimated one from available data, the real errors might be substantially higher, increasing the uncertainty of computed loads (Rode and Suhr 2007; Salles et al. 2008).

However, it should be noted that integrated sampling also has practical drawbacks in sample collection (e.g., Allan et al. 2006) which should be taken into consideration while planning a sampling strategy. Collection of integrated samples using automatic samplers requires prior acidification of bottles to prevent metal loss from solution. Then, since the part of metal weakly bound to particles is released to the solution the measured concentrations should be considered as "labile". To facilitate accurate apportion between dissolved and particulate loads, preliminary tests should be performed at each sampling site to estimate the metal fraction desorbed from suspension in receiving bottles due to the addition of acid.

\section{Conclusions}

This study has demonstrated that an impoundment reservoir plays an important role in chromium transport not only in the particulate but also in the dissolved phase. Concentration decrease of both chromium forms was observed after transport through the reservoir. Subsequent transport through a compensatory reservoir did not produce such noteworthy changes in concentrations due to the much shorter residence
Fig. 3 Weekly evolution of labile fraction of total chromium $\left(\mathrm{Cr}_{\text {lab }}\right)$ loads and water discharge at site 1 (Dunajec River) during the sampling period

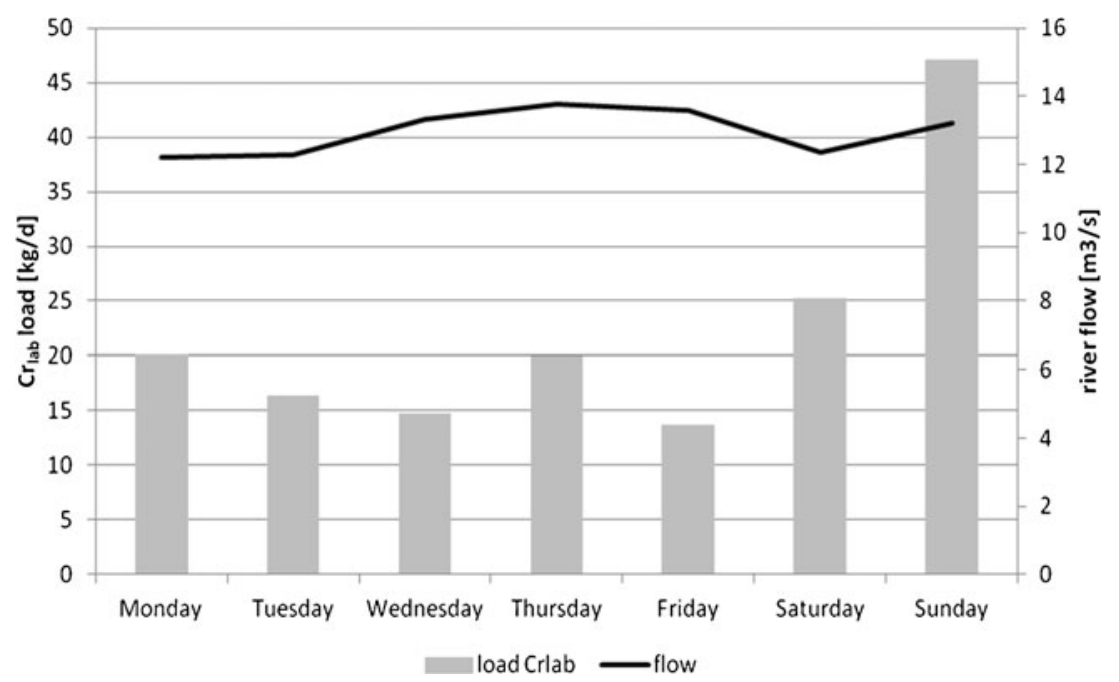


time. Moreover, comparison of chromium loads, calculated on the basis of the integrated sampling mode, showed that retention efficiency of the impoundment reservoir reaches 74-94\% for dissolved chromium. A lower percentage of retained particulate chromium (42\%) is related to higher concentrations of particulate matter in the outlet of the reservoir due to the lowered water level (maintenance works) and related sediment erosion. At these particular conditions, the contaminants stored within the sediments can be released to the downstream reaches of the river.

Implementation of two different sampling regimes, instantaneous and integrated, allowed not only for tracking variability of chromium sources but also for investigation of sampling mode impact on load calculations. Differences between chromium concentrations measured in instantaneous (discrete) and time-integrated (daily or weekly averages) samples showed that chromium contamination in the river is variable and discontinuous due to fluctuating source characteristics. Moreover, instantaneous sampling can lead to an underestimation of chromium contamination level in the watershed. The main reason was due to illegal discharges during weekends, and possibly at nights when discrete sampling for monitoring is not carried out. From chromium load computations based on results of both types of samples, we also concluded that integrated sampling produces more reliable data with an acceptable range of estimate errors. Instantaneous sampling, even if frequent, should not be used for contaminant budget calculations in localities where strong variability of contamination is anticipated.

Acknowledgments The authors would like express their thanks to Michal Krzyszkowski (Niedzica Hydro-Electric Power Plant) for his help in the field work. Analytical work performed at the Institute F.A. Forel and the Cracow University of Technology was supported by the Swiss National Science Foundation (grant no: 200020-1179).

Open Access This article is distributed under the terms of the Creative Commons Attribution License which permits any use, distribution, and reproduction in any medium, provided the original author(s) and the source are credited.

\section{References}

Allan IJ, Vrana B, Greenwood R, Mills GA, Roig B, Gonzalez C (2006) A "toolbox" for biological and chemical monitoring requirements for the European Union's Water Framework Directive. Talanta 69:302-322

Dominik J, Bas B, Bobrowski A, Dworak T, Koukal B, Niewiara E, Pereira de Abreu M-H, Rosee P, Szalinska E, Vignati D (2003) Partitioning of chromium(VI) and chromium(III) between dissolved and colloidal forms in a stream and reservoir contaminated with tannery waste water. J Phys IV 107:385-388

Dominik J, Vignati DAL, Koukal B, Pereira de Abreu M-H, Kottelat R, Szalinska E, Bas B, Bobrowski A (2007) Speciation and environmental fate of chromium in rivers contaminated with tannery effluents. Eng Life Sci 7:155-169

Honeyman JT, Santschi PH (1992) The role of particles and colloids in the transport of radionuclides and trace metals in the oceans. In: Buffle J, Van Leeuwen HP (eds) Environmental Particles, vol.1, IUPAC Series on Environmental, Analytical and Physical Chemistry. Lewis Publishers, Chelsea, pp 379-423

Johnes PJ (2007) Uncertainties in annual riverine phosphorus load estimation: impact of load estimation methodology, sampling frequency, baseflow index and catchment population density. J Hydrol 332:241-258

Klaver G, van Os B, Negrel P, Petelet-Giraud E (2007) Influence of hydropower dams on the composition of the suspended and riverbank sediments in the Danube. Environ Pollut 148:718-728

Osol (1986) Directive on threats to soils. RS 814.015. Le Conseil Féderal Suisse (in French)

Priadi C, Bourgeault A, Ayrault S, Gourlay-Francé C, Tusseau-Vuillemin M-H, Bonté P, Mouchel J-M (2011) Spatio-temporal variability of solid, total dissolved and labile metal: passive vs. discrete sampling evaluation in river metal monitoring. J Environ Monit 13:14701479

Rode M, Suhr U (2007) Uncertainties in selected river quality data. Hydrol Earth Syst Sci 11:863-874

Salles C, Tournoud MG, Chu Y (2008) Estimating nutrient and sediment flood loads in a small Mediterranean river. Hydrol Processes 22:242-253

Sundborg A (1992) Lake and reservoir sedimentation. Prediction and interpretation. Geogr Ann 74A:93-100

Szalinska E (2002) Chromium transformations in the water environment contaminated with tannery waste water. Monographs of Cracow University of Technology 283, issue: Environmental Engineering (in Polish)

Szalinska E, Dominik J, Vignati DAL, Bobrowski A, Bas B (2010) Seasonal transport pattern of chromium (III and VI) in a stream receiving wastewater from tanneries. Appl Geochem $25: 116-122$

Vörösmarty CJ, Meybeck M, Fekete B, Sharma K, Green P, James PM, Syvitski JPM (2003) Anthropogenic sediment retention: major global impact from registered river impoundments. Glob Planet Chang 39:169-190

Webb BW, Phillips JM, Walling DE, Littlewood IG, Watts CD, Leeks GJL (1997) Load estimation methodologies for British rivers and their relevance to the LOIS RACS(R) programme. Sci Total Environ 194/195:379-389

Webb BW, Phillips JM, Walling DE (2000) A new approach to deriving "best estimate" chemical fluxes for rivers draining the LOIS study area. Sci Total Environ 251/252:45-54 